\title{
The Use of Intravenous Immunoglobulin in Subacute Sclerosing Panencephalitis: A Retrospective Cohort Study
}

\author{
Marissa B. Lukban, ${ }^{1,2}$ Bernadette C. Chua-Macrohon ${ }^{3}$ and Aida M. Salonga ${ }^{1,4}$ \\ ${ }^{1}$ Department of Pediatrics, College of Medicine and Philippine General Hospital, University of the Philippines Manila \\ ${ }^{2}$ Department of Neurosciences, College of Medicine and Philippine General Hospital, University of the Philippines Manila \\ ${ }^{3}$ Department of Pediatrics, Zamboanga City Medical Center, Ateneo de Zamboanga University - School of Medicine, Zamboanga City, Philippines \\ ${ }^{4}$ Institute of Child Health, National Institutes of Health, University of the Philippines Manila
}

\begin{abstract}
Objective. To determine the effect of intravenous immunoglobulin (IVlg) on the outcome of patients with Subacute Sclerosing Panencephalitis (SSPE).

Methods. This is a retrospective cohort of patients enrolled in the Philippine General Hospital SSPE registry. The clinical stage of patients who received Inosiplex plus IVIg was compared with controls (Inosiplex alone) serially at 1, 3, 6 and 12 months after initiation of treatment. Clinical response was reported as improved, unchanged, worsened or death, compared to the baseline clinical stage. Outcomes between those who received IVIg at Stage I and II disease were compared to those who received IVIg at Stage III.
\end{abstract}

Results. Twenty one percent of patients who received IVlg showed clinical improvement after one month of treatment compared to none in the control group. The significant favorable outcome in the IVlg group was seen among patients who received treatment at Stages I and II of illness and was sustained for 3 months. The outcome of patients in SSPE Stage III was not significantly different between the two treatment groups. Mortality rate by 12 months was similar in both groups in all stages.

Conclusion. Intravenous immunoglobulin may produce a transient improvement in patients with SSPE up to the third month after administration especially among patients who receive treatment during the earlier stages of the disease, but improvement is not sustained.

Key Words: intravenous immunoglobulin, subacute sclerosing panencephalitis

\section{Introduction}

Subacute sclerosing panencephalitis (SSPE) is a slowly progressive, but invariably fatal, central nervous system (CNS) complication of measles infection, characterized by

Corresponding author: Marissa B. Lukban, MD

Department of Pediatrics

Philippine General Hospital

University of the Philippines Manila

Taft Avenue, Ermita, Manila 1000 Philippines

Telephone: +6325240892

Email: mblukban@yahoo.com subacute to chronic deterioration in cognitive and motor function several years after the primary infection. While the exact pathogenesis of SSPE remains to be determined, it is believed to be due to the interplay of contributions coming from the measles virus (MV), the immune status of the host and existing environment at the time of acute measles infection.

In normal individuals, antigen presentation allows the immune system to respond through inhibition by cytotoxic $\mathrm{T}$ lymphocytes. In SSPE, despite the presence of the antigen, the immune system fails. Several studies suggest a functional abnormality of thymus-dependent lymphocytes and deficient cellular immunity. Gerson analyzed the response of four boys with SSPE to intradermal injection of antigens and to the application of skin grafts. All the boys showed either absent or greatly decreased response to both stimuli even with normal lymphocyte count. ${ }^{1}$

The failure of the immune system to eliminate the virus is due to several contributing factors. Foremost is the accumulation of mutations in the MV envelope with the matrix gene harboring the most mutations. When MV matrix protein expression is reduced, the MV remains viable and persists despite high levels of anti-measles antibody titers in the serum and CSF. In addition, interferon response to the infected neurons is deficient and inadequate in SSPE. ${ }^{2}$ Hara measured the production of MV-specific T helper 1 (Th1) and $\mathrm{T}$ helper 2 (Th2) cytokines by peripheral blood mononuclear cells in response to live measles, mumps or varicella virus. In this study, he observed that there was a decrease in the MV-specific production of interferon $\gamma$, aTh1 cytokine, with intact production of IL-4 and IL-2, which are Th2 cytokines. Moreover, upon stimulation with viral antigens, it was noted that SSPE patients who had a substantial response in interferon $\gamma$ production eventually developed better cognitive response later on in the disease. ${ }^{3}$

The exact mechanism of action of intravenous immunoglobulin has been determined to employ various modes of action. Neutralization of pathogenic autoantibodies, inhibition of complement binding and prevention of membranolytic attack complex (MAC) formation, and modulation and blockade of the Fc receptor are among the established modes of action. ${ }^{4}$ Its role in T-cell 
mediated immunity, however, has not been clearly delineated, although there has been evidence suggesting that IVIg suppresses the production of pathogenic cytokines. ${ }^{5}$

There is no definite eradicative medical treatment for SSPE. Oral Inosiplex have been used since the 1960's and some studies have shown that Inosiplex can slow disease progression and increase survival time but none reports cure among those treated compared to retrospective historical controls. ${ }^{6,7}$ In 1996, Gurer et al. reported significant improvement in a 10-year-old boy with the use of intravenous immunoglobulin (IVIg). ${ }^{8}$ With a follow-up of 18 months, neurological disability scores showed a decline from Stage III to Stage I disease and suggested IVIg as an alternative therapy for SSPE. In 1999, Lukban et al. reported the experience of using IVIg for a series of SSPE patients. In this review, there was note of a transient improvement in the receptive and cognitive function of the patients. ${ }^{9}$

This study has been undertaken to compare the clinical outcome of SSPE patients who received IVIg in addition to Inosiplex to those who did not.

\section{Methods}

\section{Subject Population}

Pediatric patients (less than 19 years of age) seen at Philippine General Hospital from January 1996 to March 2002, diagnosed with SSPE based on a typical or atypical clinical course and elevated cerebrospinal fluid (CSF) measles-specific antibody titers were included in the study. The control group consisted of SSPE subjects who received the standard treatment of oral Inosiplex at $50-100 \mathrm{mg} / \mathrm{kg} /$ day only. The study group (IVIg Group) comprised of SSPE subjects who refused inclusion in an ongoing randomized controlled trial on intraventricular interferon and instead requested for an alternative drug therapy. The alternative drug therapy offered was IVIg given at $400 \mathrm{mg} / \mathrm{kg}$ per day for 5 days in addition to oral Inosiplex. Informed consent was obtained from parents following full explanation of the experimental nature of the treatment. Both groups received appropriate anti-epileptic drugs.

\section{Study Design}

Retrospective cohort study

\section{Methods}

The medical records of subjects in both groups were retrieved and the clinical course and physical examination findings were reviewed to determine the SSPE clinical staging from the onset of the disease and serially (Table 1). ${ }^{10}$ Clinical staging was based on the clinical manifestations, neurologic examination and functional status of each patient during the course of illness. When applicable, the difference in baseline characteristics between the study and the control group was computed using Fischer's exact test.
Table 1. Clinical stages of SSPE by Jabbour

\begin{tabular}{|c|c|}
\hline $\begin{array}{l}\text { Clinical } \\
\text { Stage }\end{array}$ & Clinical Manifestations \\
\hline IA & Behavioral, cognitive, personality changes \\
\hline IB & Myocolonic spasms; aperiodic, focal, subtle, infrequent \\
\hline IIA & $\begin{array}{l}\text { Myoclonic spasms; periodic, generalized, synchronous, } \\
\text { frequent }\end{array}$ \\
\hline IIB & $\begin{array}{l}\text { Apraxia, agnosias, speech/language, spasticity, ataxia. } \\
\text { Ambulatory with assistance }\end{array}$ \\
\hline IIIA & $\begin{array}{l}\text { Spasms frequent and multifocal. Sits independently, may } \\
\text { stand, no walking, dependent on activities of daily living, } \\
\text { Speaks less and have visual difficulties }\end{array}$ \\
\hline IIIB & $\begin{array}{l}\text { Bedridden, no spontaneous speech, poor comprehension, } \\
\text { may be blind, with dysphagia, with involuntary } \\
\text { movements (chorea-ballismus-athetosis) }\end{array}$ \\
\hline IV & Neurovegetative state and loss of myoclonic jerks. \\
\hline
\end{tabular}

For subjects in the study group, the SSPE clinical stage was noted at the time prior to initiation of IVIg treatment (baseline) and at 1, 3, 6, and 12 months after. For subjects in the control group, the SSPE clinical staging was noted from the $7^{\text {th }}$ month of illness (baseline), which corresponds to the mean time of initiation of IVIg treatment in the study group, and at 1, 3, 6, and 12 months of illness after the baseline.

Clinical response was reported as (1) improved, (2) unchanged (3) worsened or (4) death, as compared to the baseline clinical stage. Improvement is defined as a change to a better or lower clinical stage and worsening is defined as a change to a poorer or higher clinical stage. Observations on change in seizure frequency, social interaction, verbal communication and quality of ambulation were also recorded. Those patients who did not report for follow-up at the specified period of observation were considered lost or drop-outs.

Analysis of data was based on the frequencies of the number of subjects in each subgroup at the different periods of observation. A comparison of proportions was performed using $\mathrm{z}$ test and significant difference between the IVIg and the control group was tabulated. A $P$ value of less than 0.05 was considered significant.

In addition, based on the baseline clinical staging, the subjects in both groups were further subdivided into 2 subsets, those in Stages I and II (Group A) and those in Stages III and IV (Group B). An outcome was considered favorable if the patients improved to a better stage. Unfavorable outcome included no change in clinical stage, worsening or death on subsequent follow-up observations. The difference in mortality rate at 12 months was also compared between the two groups.

\section{Results}

\section{Patient Characteristics}

There were 33 patients in the IVIg group, 25 males and 8 females, with the male to female ratio of 3.1:1 and a mean age of 9.8 years (range $5-18$ years) (Table 2). The mean duration of illness prior to the IVIg treatment was 7 months 
(range 1-24 months). The stages of the disease ranged from IB to IIIB, with the largest number $(11 / 33$ or $33 \%)$ in Stage IIIA at the time of IVIg treatment (Figure 1). The mean duration of follow-up of patients who received IVIg was 14.2 months.

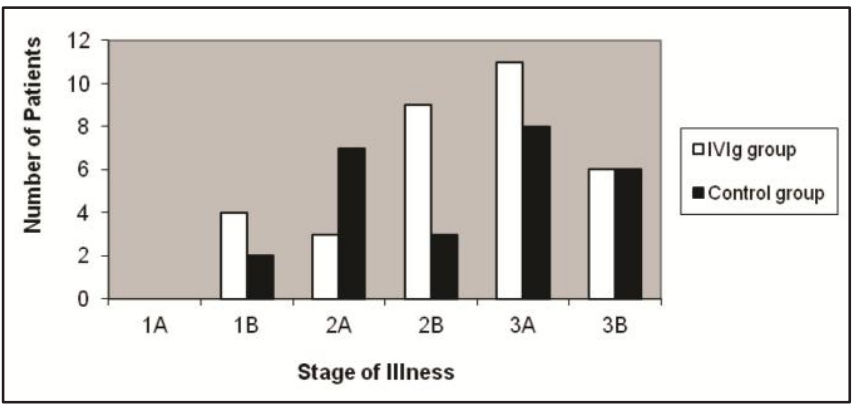

Figure 1. Distribution of SSPE patients according to the Stage of Illness at Baseline.

Table 2. Patient characteristics of the IVIg group and the control group

\begin{tabular}{|c|c|c|c|}
\hline & $\begin{array}{c}\text { IVIg Group } \\
\mathrm{N}=33\end{array}$ & $\begin{array}{c}\text { Control Group } \\
\mathrm{N}=26\end{array}$ & p value ${ }^{*}$ \\
\hline \multicolumn{4}{|l|}{ Age } \\
\hline Mean & 9.8 years & 10.1 years & ----- \\
\hline Range & $5-18$ years & $4-18$ years & \\
\hline \multicolumn{4}{|l|}{ Sex } \\
\hline Male & 25 & 17 & 0.4029 \\
\hline Female & 8 & 9 & \\
\hline Male to female ratio & $3.1: 1$ & $1.9: 1$ & \\
\hline \multicolumn{4}{|c|}{ History of Measles Infection } \\
\hline Yes & 29 & 24 & 0.6852 \\
\hline No & 4 & 2 & \\
\hline \multicolumn{4}{|l|}{ Age of Measles Infection } \\
\hline Mean & 16.8 months & 18.6 months & ---- \\
\hline Range & $5-96$ months & $4-94$ months & \\
\hline \multirow{2}{*}{\multicolumn{4}{|c|}{$\begin{array}{l}\text { Duration of illness prior to } \\
\text { IVIg treatment/baseline } \\
\text { evaluation }\end{array}$}} \\
\hline & & & \\
\hline Mean & 7 months & 7 months & ----- \\
\hline Range & $1-24$ months & ----- & \\
\hline \multicolumn{4}{|l|}{ Duration of follow-up } \\
\hline Mean & 14.2 months & 9 months & ---- \\
\hline Range & $1-40$ months & $1-36$ months & \\
\hline Clinical Stage & & & 1.00 \\
\hline \multicolumn{4}{|l|}{ Group A } \\
\hline Stage 1 & 4 & 2 & \\
\hline Stage 2 & 12 & 10 & \\
\hline Total & 16 & 12 & \\
\hline \multicolumn{4}{|l|}{ Group B } \\
\hline Stage 3 & 17 & 14 & \\
\hline Stage 4 & 0 & 0 & \\
\hline Total & 17 & 14 & \\
\hline
\end{tabular}

The control group consisted of 26 patients, 17 males and 9 females with a male to female ratio of 1.9:1. Their mean age was 10.1 years (range $4-18$ years). Similar to the IVIg group, the stages of the disease at the $7^{\text {th }}$ month of illness ranged from IB to IIIB, with the largest percentage of patients $(8 / 26$ or $30.8 \%)$ in Stage IIIA (Figure 1$)$. The mean duration of follow-up was 9 months.

There was no significant difference between the two treatment groups in terms of gender, past history of measles infection and baseline clinical stage.

\section{Clinical outcome at 1 month}

Twenty one percent (7/33) of those in the IVIg group improved clinically within 1 month of administration of IVIg, but none in the control group. However, 24\% (8/33) in the IVIg group also worsened. Majority in both groups, 55\% $(18 / 33)$ in the IVIg group and $96 \%(25 / 26)$ in the control group remained in the same clinical stage. The differences in the outcomes between the two groups were statistically significant (Table 3).

On subgroup analysis, the significant number of patients who improved (5/7 or $71 \%$ ) belonged to those who received treatment while in Stages I and II of the disease. Among the patients in Stage III, the outcomes were not significantly different between the IVIg and the control group.

\section{Clinical outcome at 3 Months}

Table 3 further describes the patients' response at 3 months after IVIg treatment and during the same time period in the control group. There was still a significantly higher percentage of patients who remained improved after IVIg administration and this was more evidently seen among patients in Stages I and II of the disease. Majority of the patients remained in their baseline clinical stage in both groups (15/33 or $45 \%$ in the IVIg and $18 / 26$ or $69 \%$ in the control group) and the difference between these two groups was now no longer statistically significant. A significant number of patients in the control group who remained unchanged or stable were in clinical Stages I and II. Again in both groups, there was no significant difference in clinical outcome among patients in Stage III of illness (Table 3).

On subgroup analysis, the significant difference in favorable outcome among patients in Stage I and II illness seen during the first month of treatment remained statistically significant at 3 months after treatment. In addition, both groups showed unfavorable outcome in the majority of the patients who were in Stage III of illness.

A number of patients were lost to follow-up in both groups during this month, $3(9 \%)$ in the IVIG group and 5 $(19 \%)$ in the control group, but the difference was not significant.

\section{Clinical outcome at 6 and 12 months}

Table 4 shows that there was no statistically significant difference in the clinical response and outcome of the two treatment groups from 6 months onwards. By the $12^{\text {th }}$ month of observation, the number of patients who initially showed improvement in the IVIg group after the $1^{\text {st }}$ and $3^{\text {rd }}$ month of 
IVIg administration had decreased from $21 \%(7 / 33)$ to $6 \%$ (2/33). Similarly, the number of patients whose clinical stage remained unchanged had decreased from 55\% (18/33) to $24 \%$ (8/33). Only one additional patient worsened from the $3^{\text {rd }}$ to the $12^{\text {th }}$ month. Nine $(27 \%)$ patients were lost to follow-up by the $6^{\text {th }}$ month which increased to thirteen $(39 \%)$ patients on the $12^{\text {th }}$ month.

Table 3. Clinical outcome of IVIg group at 1 and 3 months after IVIg treatment compared to the control group

\begin{tabular}{|c|c|c|c|c|c|c|}
\hline & \multicolumn{3}{|c|}{1 month of treatment } & \multicolumn{3}{|c|}{3 months of treatment } \\
\hline & $\begin{array}{l}\text { IVIg } \\
\text { group } \\
\text { N (\%) } \\
\end{array}$ & $\begin{array}{l}\text { Control } \\
\text { group } \\
\mathrm{N}(\%) \\
\end{array}$ & $\mathrm{p}$ value & $\begin{array}{c}\text { IVIg } \\
\text { Group } \\
\text { N (\%) } \\
\end{array}$ & $\begin{array}{l}\text { Control } \\
\text { Group } \\
\text { N (\%) } \\
\end{array}$ & p-value \\
\hline \multicolumn{7}{|l|}{ Patient Status: Overall } \\
\hline Improved & $7(21)$ & $0(0)$ & $0.004^{*}$ & $6(18)$ & $0(0)$ & $0.008^{*}$ \\
\hline Unchanged & $18(55)$ & $25(96)$ & $<0.001^{*}$ & $15(45)$ & $18(69)$ & 0.060 \\
\hline Worsened & $8(24)$ & $1(4)$ & $0.019^{*}$ & $9(27)$ & $3(12)$ & 0.141 \\
\hline Lost to follow up & $0(0)$ & $0(0)$ & ---- & $3(9)$ & $5(19)$ & 0.284 \\
\hline Death & $0(0)$ & $0(0)$ & ----- & $0(0)$ & $0(0)$ & ---- \\
\hline Total & $33(100)$ & $26(100)$ & & $33(100)$ & $26(100)$ & \\
\hline \multicolumn{7}{|c|}{ Patient Status: Stages 1 - 2} \\
\hline Improved & $5(31)$ & $0(0)$ & $0.009^{*}$ & $5(31)$ & $0(0)$ & $0.009^{*}$ \\
\hline Unchanged & $5(31)$ & $12(100)$ & $<0.001^{*}$ & $4(25)$ & $9(75)$ & $0.004^{*}$ \\
\hline Worsened & $6(38)$ & $0(0)$ & $0.002^{*}$ & $7(44)$ & $2(17)$ & 0.114 \\
\hline Lost to follow-up & $0(0)$ & $0(0)$ & ----- & $0(0)$ & $1(8)$ & 0.328 \\
\hline Death & $0(0)$ & $0(0)$ & ----- & $0(0)$ & $0(0)$ & ----- \\
\hline Total & $16(100)$ & $12(100)$ & & $16(100)$ & $12(100)$ & \\
\hline \multicolumn{7}{|c|}{ Patient Status: Stages $3-4$} \\
\hline Improved & $2(12)$ & $0(0)$ & 0.140 & $1(6)$ & $0(0)$ & 0.312 \\
\hline Unchanged & $13(76)$ & $13(93)$ & 0.185 & $11(65)$ & $9(64)$ & 0.955 \\
\hline Worsened & $2(12)$ & $1(7)$ & 0.643 & $2(12)$ & $1(7)$ & 0.643 \\
\hline Lost to follow-up & $0(0)$ & $0(0)$ & ------ & $3(18)$ & $4(28)$ & 0.525 \\
\hline Death & $0(0)$ & $0(0)$ & ------ & $0(0)$ & $0(0)$ & ----- \\
\hline Total & $17(100)$ & $14(100)$ & & $17(100)$ & $14(100)$ & \\
\hline \multicolumn{7}{|c|}{ Clinical Outcome } \\
\hline \multicolumn{7}{|c|}{$\begin{array}{l}\text { Patient Status: Stages } 1-2 \\
\text { (Group A) }\end{array}$} \\
\hline Favorable & $5(31)$ & $0(0)$ & $0.009^{*}$ & $5(31)$ & $0(0)$ & $0.009^{*}$ \\
\hline Unfavorable & $11(69)$ & $12(100)$ & $0.009^{*}$ & $11(69)$ & $11(92)$ & 0.112 \\
\hline Lost to follow-up & $0(0)$ & $0(0)$ & ----- & $0(0)$ & $1(8)$ & 0.328 \\
\hline Total & $16(100)$ & $12(100)$ & & $16(100)$ & $12(100)$ & \\
\hline \multicolumn{7}{|c|}{$\begin{array}{l}\text { Patient Status: Stages } 3-4 \\
\text { (Group B) }\end{array}$} \\
\hline Favorable & $2(12)$ & $0(0)$ & 0.140 & $1(6)$ & $0(0)$ & 0.312 \\
\hline Unfavorable & $15(88)$ & $14(100)$ & 0.140 & $13(76)$ & $10(71)$ & 0.762 \\
\hline Lost to follow-up & $0(0)$ & $0(0)$ & ---- & $3(18)$ & $4(29)$ & 0.487 \\
\hline Total & $17(100)$ & $14(100)$ & & $17(100)$ & $14(100)$ & \\
\hline \multicolumn{7}{|c|}{ Patient Status: Stages $3-4$} \\
\hline Improved & $1(6)$ & $0(0)$ & 0.312 & $0(0)$ & $0(0)$ & ----- \\
\hline Unchanged & $7(41)$ & $3(21)$ & 0.231 & $7(41)$ & $3(21)$ & 0.231 \\
\hline Worsened & $2(12)$ & $1(7)$ & 0.623 & $1(6)$ & $0(0)$ & 0.312 \\
\hline Lost to follow-up & $7(41)$ & $9(64)$ & 0.204 & $9(53)$ & $10(72)$ & 0.281 \\
\hline Mortality & $0(0)$ & $1(7)$ & 0.323 & $0(0)$ & $1(7)$ & 0.324 \\
\hline Total & $17(100)$ & $14(100)$ & & $17(100)$ & $14(100)$ & \\
\hline \multicolumn{7}{|c|}{ Clinical Outcome } \\
\hline \multicolumn{7}{|c|}{$\begin{array}{l}\text { Patient Status: Stages } 1 \text { - } 2 \\
\text { (Group A) }\end{array}$} \\
\hline Favorable & $2(12.5)$ & $1(8)$ & 0.704 & $4(25)$ & $5(42)$ & 0.361 \\
\hline Unfavorable & $12(75)$ & $8(67)$ & 0.700 & $8(50)$ & $3(26)$ & 0.194 \\
\hline Lost to follow-up & $2(12.5)$ & $3(25)$ & 0.423 & $4(25)$ & $4(33)$ & 0.658 \\
\hline Total & $16(100)$ & $12(100)$ & & $16(100)$ & $12(100)$ & \\
\hline \multicolumn{7}{|c|}{$\begin{array}{l}\text { Patient Status: Stages } 3-4 \\
\text { (Group B) }\end{array}$} \\
\hline Favorable & $1(6)$ & $0(0)$ & 0.312 & $0(0)$ & $0(0)$ & ---.- \\
\hline Unfavorable & $9(53)$ & $5(36)$ & 0.352 & $08(47)$ & $4(33)$ & 0.438 \\
\hline Lost to follow-up & $7(41)$ & $9(64)$ & 0.204 & $9(53)$ & $10(66)$ & 0.473 \\
\hline Total & $17(100)$ & $14(100)$ & & $17(100)$ & $14(100)$ & \\
\hline
\end{tabular}

Table 4. Clinical outcome of IVIg group at 6 and 12 months after IVIg treatment compared to the control group

\begin{tabular}{|c|c|c|c|c|c|c|}
\hline & \multicolumn{3}{|c|}{6 months of treatment } & \multicolumn{3}{|c|}{12 months of treatment } \\
\hline & $\begin{array}{c}\text { IVIg } \\
\text { Group } \\
\text { N (\%) } \\
\end{array}$ & $\begin{array}{l}\text { Control } \\
\text { Group } \\
\text { N (\%) }\end{array}$ & p-value & $\begin{array}{c}\text { IVIg } \\
\text { Group } \\
\text { N (\%) } \\
\end{array}$ & $\begin{array}{c}\text { Control } \\
\text { Group } \\
\text { N (\%) }\end{array}$ & p-value \\
\hline \multicolumn{7}{|l|}{ Patient Status: Overall } \\
\hline Improved & $3(9)$ & $1(4)$ & 0.435 & $2(6)$ & $2(8)$ & 0.771 \\
\hline Unchanged & $11(33)$ & $8(31)$ & 0.872 & $8(24)$ & $6(23)$ & 0.930 \\
\hline Worsened & $9(27)$ & $3(11)$ & 0.111 & $9(27)$ & $2(8)$ & 0.05 \\
\hline Lost to follow-up & $9(27)$ & $12(46)$ & 0.134 & $13(39)$ & $14(53)$ & 0.289 \\
\hline Mortality & $1(3)$ & $2(8)$ & 0.420 & $1(3)$ & $2(8)$ & 0.421 \\
\hline Total & $33(100)$ & $26(100)$ & ---- & $33(100)$ & $26(100)$ & ---- \\
\hline \multicolumn{7}{|c|}{ Patient Status: Stages 1 - 2} \\
\hline Improved & $2(13)$ & $1(8)$ & 0.675 & $2(13)$ & $2(17)$ & 0.779 \\
\hline Unchanged & $4(25)$ & $5(42)$ & 0.361 & $2(13)$ & $3(25)$ & 0.444 \\
\hline Worsened & $7(44)$ & $2(17)$ & 0.114 & $7(44)$ & $2(17)$ & 0.114 \\
\hline Lost to follow-up & $2(12)$ & $3(25)$ & 0.402 & $4(24)$ & $4(33)$ & 0.616 \\
\hline Mortality & $1(6)$ & $1(8)$ & 0.845 & $1(6)$ & $1(8)$ & 0.845 \\
\hline Total & $16(100)$ & $12(100)$ & & $16(100)$ & $12(100)$ & \\
\hline \multicolumn{7}{|c|}{ Patient Status: Stages $3-4$} \\
\hline Improved & $1(6)$ & $0(0)$ & 0.312 & $0(0)$ & $0(0)$ & ------ \\
\hline Unchanged & $7(41)$ & $3(21)$ & 0.231 & $7(41)$ & $3(21)$ & 0.231 \\
\hline Worsened & $2(12)$ & $1(7)$ & 0.623 & $1(6)$ & $0(0)$ & 0.312 \\
\hline Lost to follow-up & $7(41)$ & $9(64)$ & 0.204 & $9(53)$ & $10(72)$ & 0.281 \\
\hline Mortality & $0(0)$ & $1(7)$ & 0.323 & $0(0)$ & $1(7)$ & 0.324 \\
\hline Total & $17(100)$ & $14(100)$ & & $17(100)$ & $14(100)$ & \\
\hline \multicolumn{7}{|c|}{ Clinical Outcome } \\
\hline \multicolumn{7}{|c|}{$\begin{array}{l}\text { Patient Status: Stages } 1-2 \\
\text { (Group A) }\end{array}$} \\
\hline Favorable & $2(12.5)$ & $1(8)$ & 0.704 & $4(25)$ & $5(42)$ & 0.361 \\
\hline Unfavorable & $12(75)$ & $8(67)$ & 0.700 & $8(50)$ & $3(26)$ & 0.194 \\
\hline Lost to follow-up & $2(12.5)$ & $3(25)$ & 0.423 & $4(25)$ & $4(33)$ & 0.658 \\
\hline Total & $16(100)$ & $12(100)$ & & $16(100)$ & $12(100)$ & \\
\hline \multicolumn{7}{|c|}{$\begin{array}{l}\text { Patient Status: Stages } 3-4 \\
\text { (Group B) }\end{array}$} \\
\hline Favorable & $1(6)$ & $0(0)$ & 0.312 & $0(0)$ & $0(0)$ & ---- \\
\hline Unfavorable & $9(53)$ & $5(36)$ & 0.352 & $08(47)$ & $4(33)$ & 0.438 \\
\hline Lost to follow-up & $7(41)$ & $9(64)$ & 0.204 & $9(53)$ & $10(66)$ & 0.473 \\
\hline Total & $17(100)$ & $14(100)$ & & $17(100)$ & $14(100)$ & \\
\hline
\end{tabular}

Similarly, in the control group, the number of patients whose clinical stage remained unchanged in the $1^{\text {st }}$ month decreased from $96 \%(25 / 26)$ to $23 \%(6 / 26)$ by the $12^{\text {th }}$ month. There was clinical improvement seen in $2(8 \%)$ patients in Stage I and II illness. Two (2) patients ( $8 \%$ ) worsened over time. However, the outcome of almost half of the patients in the control group, $12(46 \%)$ in the $6^{\text {th }}$ month and $14(53 \%)$ by the $12^{\text {th }}$ month, was unknown as they were lost to follow-up. The number of subjects lost to follow-up between the IVIg and the control group was not statistically significant.

\section{Mortalities}

All mortalities occurred between the $3^{\text {rd }}$ to $6^{\text {th }}$ month of observation in both groups, 1 patient in the IVIg group and 2 patients in the control group. The difference in mortality between the two groups was not significant.

\section{Discussion}

There is still no definitive cure for SSPE. Gurer's initial report of the successful use of IVIg in one patient offered an alternative medication for SSPE. This study comparing the outcomes of patients after the administration of IVIg 
supports his theory that in some patients, especially those who are in an earlier SSPE stage, IVIg may give a beneficial effect. In this study and in the series reported by Lukban and co-workers, parents and caretakers of children who received IVIg have noticed marked improvement in the patients' social interaction, reported as the establishment of visual regard, more appropriate emotional response, and attempts at verbal interaction. ${ }^{9}$ There was also note of a decrease in myoclonic jerks in some. However, among those who showed improvement, the favorable response was transient and not sustained beyond 3 months. This may be explained by the half-life of IVIg which is approximately 18-32 days. ${ }^{4}$

However, our data also shows that a significant number of patients in the IVIg group worsened by one month after the administration of IVIg. The use of IVIg, as mentioned previously, employs various modes of action theoretically. In the context of SSPE where it is hypothesized that there is a decrease in T cell function, ${ }^{1-3}$ IVIg is believed to be able to enhance $\mathrm{T}$ cell function by neutralizing viral superantigens. ${ }^{11}$ These neutralizing antibodies, in turn, may activate $\mathrm{T}$ cells non-specifically. However, some studies have shown that IVIg can also block $\mathrm{T}$ cell activation by the presence of soluble CD4, CD8, and major histocompatibility complex (MHC) molecules which act as antagonist of the $\mathrm{T}$ cell receptor. IVIg may also contain antibodies against the $\mathrm{T}$ cell receptor $\beta$-chain which can also block $\mathrm{T}$ cell activation and these may explain the worsening of some patients in the IVIg group compared to the controls. ${ }^{11}$ In addition, the control group continued to receive Inosiplex which may slow disease progression. ${ }^{6-7}$ The disease modifying effect of IVIg is not seen among patients who received treatment during the latter stages of illness.

By the $6^{\text {th }}$ to $12^{\text {th }}$ month of observation, there was no significant difference in the outcome and mortality of patients who received IVIg and those who did not. This appears to be mainly due to the increasing number of patients lost to follow-up especially among those in Stage III disease in both the IVIg and the control group. A life-table analysis may more appropriately show survival pattern among the different groups however, the insufficient medical data from a retrospective cohort restricts such analysis. Clinical outcome is also dependent on a variety of factors contributed by a chronic degenerative illness like SSPE, such as nutritional status, the presence of co-morbid illness, availability of nursing care, and provisions for medical services. In addition, previous reports have shown that the slowly progressive forms of SSPE have better chances of improvement to medications compared to the rapidly progressive forms. A prospective, randomized, controlled trial on the use of IVIg that can control these confounding factors is ideal but may be difficult to do.

\section{Conclusion}

The use of IVIg in SSPE produced a transient improvement in the clinical staging of the disease up to the third month of administration among patients in the earlier stages of SSPE but improvement was not sustained. At the moment, as we search for the appropriate treatment to control the progression or modify the course of SSPE, the continued use of oral Inosiplex is recommended as the mainstay in the treatment of SSPE. Adequate nutrition and nursing care, just like in any other chronic disease, should be part of the standard of care for patients with SSPE.

\section{References}

1. Gerson KL, Haslam RA. Subtle immunologic abnormalities in four boys with subacute sclerosing panencephalitis. N Engl J Med. 1971; 285(2):78-82.

2. Schneider-Schaulies. Measles Virus Persistence and Subacute Sclerosing Panencephalitis. Neuroinfection. 2008; 13(1):100-109.

3. Hara T, Yamashita S, Aiba H, et al. Measles virus-specific T helper $1 / \mathrm{T}$ helper 2-cytokine production in subacute sclerosing panencephalitis. J Neurovirol. 2000; 6(2):121-6.

4. Dalakas MC. Mechanism of action of intravenous immunoglobulin and therapeutic considerations in the treatment of autoimmune neurologic diseases. Neurology. 1998; 51(6 Suppl 5):S2-8.

5. Dalakas MC. Controlled studies with high-dose intravenous immunoglobulin in the treatment of dermatomyositis, inclusion body myositis, and polymyositis. Neurology. 1998; 51(6 Suppl 5):S37-45.

6. Jones CE, Dyken PR, Huttenlocher PR, Jabbour JT, Maxwell KW. Inosiplex therapy in subacute sclerosing panencephalitis. A multicentre, non-randomised study in 98 patients. Lancet. 1982; 1(8280):1034-7.

7. Fukuyama Y, Nihei K, Matsumoto S, et al. Clinical effects of MND-19 (Inosiplex) on subacute sclerosing panencephalitis -- a multiinstitutional collaborative study -- The Inosiplex-SSPE Research Committee. Brain Dev. 1987; 9(3):270-82.

8. Gurer YK, Kukner S, Sarica B. Intravenous gamma-globulin treatment in a patient with subacute sclerosing panencephalitis. Pediatr Neurol. 1996; 14(1):72-4.

9. Lukban MB, Salonga AM, Lu MCT, Fojas MS. The use of intravenous immunoglobulin in subacute sclerosing panencephalitis. Oral Case Presentation. Asian Oceanian Congress of Child Neurology, Malaysia, 1999.

10. Jabbour JT, Duenas DA, Modlin J. Subacute sclerosing panencephalitis: clinical staging, course and frequency. Arch Neurol. 1975; 32:493-4.

11. Hartung HP, Kieseier BC, Gold R, Archelos JJ. Intravenous Immunoglobulins: Impact on effector mechanisms in autoimmune neurological disorders. Presented in the European Neurological Society Annual Meeting, Nice, France, 1998. 